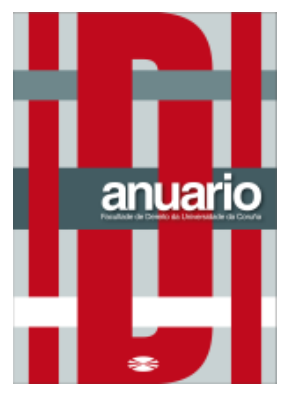

Anuario da Facultade de Dereito da Universidade da Coruña

Vol. 25 (2021), pp. 186-197

ISSNe: 2530-6324 || ISSN: 1138-039X

DOI: https://doi.org/10.17979/afdudc.2021.25.0.8804

\title{
FEIJOO, SARMIENTO Y LA POLÉMICA EN TORNO A LA ABOLICIÓN DE LA TORTURA Y LA PENA DE MUERTE
}

\section{FEIJOO, SARMIENTO AND THE CONTROVERSY SURROUNDING THE ABOLITION OF TORTURE AND THE DEATH PENALTY}

\author{
LUIS RODRÍGUEZ ENNES \\ Catedrático Emérito de Derecho Romano y Sistemas Jurídicos Comparados Universidad \\ de Vigo y R. A. de la Historia (C.) y Gallega de Jurisprudencia y Legislación (N.) \\ https://orcid.org/0000-0003-3561-1592
}

Recibido: 24/06/2021

Aceptado: 26/09/2021

Resumen: El Siglo de las Luces va a iluminar todos y cada uno de los rincones de la sociedad. En este sentido, no podía de dejar de denunciar el estado de verdadero caos en el que se encontraba la legislación criminal con su sistema de penas rígido y burlado en la práctica con demasiada frecuencia y, por ende, sin proporcionalidad entre delito y pena. De este modo, adquirió un gran relieve el debate sobre la abolición de algunas penas como las infamantes y la capital que van a ser consideradas por Feijoo y Sarmiento como contraproducentes en relación con una consideración omnímoda de la utilidad general.

Palabras clave: Ilustración, tortura, pena de muerte, abolición.

Abstract: The Enlightenment will illuminate each and every corner of society and in this sense, he could not stop denouncing the state of true chaos in which the criminal legislation was found with its rigid and mocked system of penalties, the practice too frequently and, therefore, without proportionality. In this way, the debate of the abolition of some penalties, such as the infamous and the capital, which will be considered by Feijoo and Sarmiento as counterproductive in relation to an all-round consideration of general utility.

Keywords: Enlightenment, torture, capital punishment, abolition. 
Donde la crítica de los ilustrados se manifestó con intensidad y amplitud mayores, fue en el sector penalista, en paralelo con el cambio de visión de las relaciones entre poder político y súbditos. Los ilustrados, partiendo de supuestos utilitaristas y humanitarios, elaboraron una concepción nueva de la pena que, rechazando la crueldad de los sistemas vigentes, apostaba por la certeza y la proporción justas como los medios disuasorios más idóneos para apartar del delito y atribuía a la sanción la función de enmendar al culpable, además de hacerle expiar su error. De este modo adquirió un gran relieve el debate sobre la abolición de algunas penas, como las infamantes y la capital que parecían a muchos contraproducentes en relación con una consideración omnímoda de la utilidad general. La visión que primaba el aspecto de la prevención sobre la represión quedaba también reforzada -a veces- por la propuesta de medidas de carácter social que disminuyeran la tendencia a delinquir mediante el mejoramiento de las condiciones económicas y culturales de la población ${ }^{1}$.

También se ha evitado buscar sólo en la ley o en las teorías surgidas de los hombres la explicación de los cambios que se producen en éste. La ley se utilizaba como "signo y testigo", es decir, como el elemento exterior de cambios producidos en otra parte ${ }^{2}$. "Porque es fuera del derecho -escribe Pierre Vilar ${ }^{3}$ - donde aparecen las fuerzas que exigen los cambios jurídicos. Y no hay estudio en sincronía, no hay investigación de una estructura que pueda aislarse de un pasado ni de un futuro tampoco. Las leyes son las culminaciones de los procesos y lugares de encuentro que marcan los límites del poder y de los deseos del individuo pero, a la vez, para conocer su funcionamiento real hay que ir a las zonas terminadas, es decir, allí donde está operando, en los tribunales, en las cárceles". Los escritores que hasta ahora han trazado un cuadro de conjunto de la historia de nuestro Derecho penal lo han hecho casi exclusivamente sobre la base de textos de carácter legal (códigos, etc.) sin darse cuenta de que muchos de ellos no se han aplicado nunca o lo han sido de un modo parcial tan solo. Hay que acudir preferentemente a las redacciones de derecho consuetudinario y, sobre todo, a los documentos de aplicación del derecho, que reflejan la realidad de la vida jurídica; cuando estos faltan, es imposible reconstruir el Derecho penal del correspondiente período ${ }^{4}$.

Todo el aparato de la justicia penal está encaminado a hacer lo más eficaz posible la labor de los jueces. El proceso judicial, con la tortura como herramienta indagatoria, la indefinición de las leyes, la falta de garantías procesales, el amplio arbitrio dejado en manos de los jueces para imponer las penas, el hecho de que estos participaran en las penas pecuniarias, la ausencia de considerandos que justificaran las sentencias, perseguían favorecer las acciones de la justicia y aumentar su celo en la persecución de los infractores

\footnotetext{
${ }^{1}$ Diccionario histórico de la Ilustración, Madrid, Alianza Editorial, 1998, Vv. Aa. p. 128, eds. Ferrere y Roche.

2 TRINIDAD FERNÁNDEZ, P., La reforma de la sociedad. Cárcel y delincuencia en España (siglos XVIII-XIX), Madrid, Alianza Editorial, 1991, p. 12.

${ }^{3}$ VILAR, P., Economía, Derecho, Historia, Barcelona, Ariel, 1983, p. 125.

${ }^{4}$ JIMÉNEZ DE ASÚA, L., Tratado de Derecho Penal, Buenos Aires, Editorial Losada, 1964, I, p. 698.
} 
de las leyes ${ }^{5}$. Pero, por la estructura de privilegios de la sociedad estamental, la justicia real tiene en la nobleza y la Iglesia un límite para sus acciones. Ambos estamentos conservan un alto grado de autonomía, tienen fueros particulares y un amplio margen para las actuaciones ilegales. Las desigualdades y distancias que existen entre los grupos sociales son las mismas que se mantienen entre las leyes y su aplicación. La penalidad de las monarquías absolutas encuentra su explicación en la forma de ejercicio del poder, que es fundamentalmente intimidatorio; en las propias limitaciones y en el escaso valor de la vida de los hombres. A falta de una vigilancia sobre la población, cada manifestación del poder real tenía que multiplicarse al máximo. Las penas que se imponían al que desobedecía las leyes reales seguía la misma lógica que todos los actos del monarca: se trataba de que tuvieran la mayor resonancia posible. Para ello las ceremonias se convertían en ceremonias espectaculares. En conjunto, el cuadro punitivo de las monarquías absolutas, se caracterizaba por la dureza con que se castigaba la mayoría de las penas. Se castigaba con la privación de los bienes valorados por todos que eran, fundamentalmente, el propio cuerpo, las posesiones materiales y la fama.

Aunque las características de la legislación penal española no difieren esencialmente de las extranjeras ${ }^{6}$, nuestra justicia criminal fue menos cruel. Cerdán de Tallada aseguraba en el siglo XVI la moderación de la de Castilla en comparación con la francesa $^{7}$. No aparece en nuestro ordenamiento punitivo el suplicio de la rueda, generalizado por casi toda Europa. Sin ir más lejos, el reglamento pombalino portugués de 1774 admite la tortura para casos de herejía y dogmatismo ${ }^{8}$. Aun cuando Lardizábal escribía a fines del XVI que la muerte por el fuego o las saetas había dejado de emplearse e nuestra patria, mientras la rueda, el descuartizamiento de seres vivos y el aceite hirviendo eran utilizadas todavía en algunas naciones cultas, es indudable que, por aquellos tiempos, la denominada «cuestión del tormento» seguía todavía siendo objeto de acendrada polémica. En efecto, cuando el siglo agotaba sus últimas décadas, un canónigo de Sevilla,

5 DORADO MONTERO, P., El derecho protector de los criminales, Madrid, Librería General de Victoriano Suárez, 1915; SALILLAS, R., Evolución penitenciaria de España, Madrid, Imprenta Clásica de España, 1916; sobre este último autor, cfr. FERNÁNDEZ RODRÍGUEZ, M. ${ }^{\mathrm{a}}$ D., El pensamiento penitenciario y criminológico de Rafael Salillas, Santiago de Compostela, Servicio de Publicaciones de la Universidad, 1976. Más modernamente FOUCAULT, M., Vigilar y castigar, Madrid, Editorial Siglo XXI, 1998.

${ }^{6}$ GARÇON, E., habla de un derecho penal común a los estados europeos durante la Edad Moderna que en sus rasgos generales se encuentra en la antigüedad pagana (Cfr. Droit Penal, París, Ed. Payot, 1922, p. 59).

${ }^{7}$ CERDÁN DE TALLADA, T., Verdadero Gobierno de esta Monarquía tomando por su propio sujeto la conservación de la paz, Valencia, Imprenta Viuda de Pedro de Huete, 1581, fol. 70. PEÑA, F., en el comentario a la obra de Eymerich, se inclina por los instrumentos tradicionales españoles frente a los tormentos nuevos que se idean en el extranjero, ya que eso es más propio de carnificium et crudelium quam consultorum et theologorum (cfr. EYMERICH, N., Directorium inquisitorium cum commentariis Francisci Pegnae, apud Marcum Antonium Zalterium, 1587, p. 594).

${ }^{8}$ Para justificar su empleo contra quien haya «difundido o diseminado sus perniciosas sectas», alega que «las reglas del más gran bien común de todos los estados ... la conservación de la religión pura y librada de sectas, crímenes y herejías que amenaza y arruinan sus finísimos fundamentos ... se hacen superiores a cualquiera consideración particular en favor de los atormentados ...»; siguen instrucciones muy detalladas de cómo aplicar la tortura, determinando el número de testigos, cuándo debe ser repetida y demás disposiciones (Vid., al respecto, JOBÍM, L., "La inquisición portuguesa y la Ilustración: I Proyecto de reforma de Melo Freire", en Perfiles jurídicos de la Inquisición Española ed. J.A. Escudero, Madrid, Universidad Complutense, 1989, p. 792, nt. 23). 
Pedro de Castro, defendía el empleo de la tortura en una enérgica diatriba titulada: Defensa de la tortura y leyes patrias que la establecieron e impugnación del tratado que escribió contra ella el Dr D. Alonso Maria de Acevedo ${ }^{9}$. El ya citado P. Zevallos alababa la utilidad $\mathrm{y}$ justicia de la tortura, aunque con tímidas concesiones a sus detractores ${ }^{10}$. Conviene recordar por último, que el Ilustre Colegio de Abogados de Madrid se manifestaba en 1778 favorable al uso del tormento como institución procesal penal estimándola justa, útil y "necesaria"11.

Si esto acaecía en los años finiseculares, ¿cuál sería la situación en la primera mitad del XVIII? La dureza de la legislación era manifiesta para lo que hoy no pasan de ser delitos fútiles o, incluso, en algunos casos, meras infracciones morales sin trascendencia punitiva: A los bígamos, además de la confiscación de sus bienes ${ }^{12}$, se les marcaba en la frente una Q con un hierro al rojo ${ }^{13}$; para la blasfemia, las Partidas establecieron un sistema que iba desde el embargo de bienes a los nobles y burgueses hasta una diversidad de penas impuestas a los hombres viles -azotes, marca, mutilación ${ }^{14}$. El derecho de las Recopilaciones generalizó las penas de confiscación, destierro, azotes y mutilación ${ }^{15}$.

La tortura tenía una importancia desmedida como medio de conocimiento de la existencia de culpabilidad, constituía un instrumento coercitivo cuyo fin era obtener la confesión del reo. Todo el andamiaje está entramado en orden a la consecución de la prueba perfecta: la confesión del acusado. Pues, en efecto, si ésta no se produce espontáneamente, la existencia de indicios contra un sospechoso permitía al juez someterlo a tortura ad eruendam veritatem; habida cuenta de que sólo se consideraba desvelada la verdad cuando el atormentado confesaba su culpabilidad en el acto del tormento y ratificaba su confesión después de la tortura, pero no si el torturado sostenía, antes durante y después del tormento, su inocencia. Por otra parte, la existencia de privilegios personales propios de una sociedad estamental, así, como las amplias facultades otorgadas al juez a la hora de interpretar los indicios de culpabilidad, determinaban tanto la existencia de discriminaciones en función del rango social del acusado, como la escasa o nula virtualidad práctica que cabía conceder a las normas -especialmente las contenidas en las Partidas- que exigían en todo caso la presencia de presunciones o indicios «ciertos» para que el tormento pudiera ser aplicado. La exigencia de sospechas o indicios suficientes, por un lado, y la

\footnotetext{
${ }^{9}$ Publicado en Madrid en 1778. Sobre la denominada «cuestión del tormento», vid:: MARTÍNEZ DÍEZ, G., "La tortura judicial en la legislación histórica española", en Anuario de Historia de Derecho Español 32 (1962) p. 292-293. TOMÁS Y VALIENTE, F., "La última etapa y la abolición de la tortura judicial en España", en Anales de la Universidad de La Laguna. Facultad de Derecho, 1963-1964= La tortura en España ${ }^{2}$ ed. Ariel, Madrid, 1994, p. 93 ss. Citamos por este último libro.

${ }^{10} \mathrm{El}$ P. ZEVALLOS reputa útil el tormento, porque sirve para purgar la infamia de los torturados que son hombre llenos de pecados y vicios; sin embargo, rechaza la tortura aplicada no al presunto culpable, sino a otros para que digan lo que sepan sobre el verdadero delincuente, pues, razona él, «no es delito conocer al reo de un delito» [La falsa filosofía o el ateísmo, deísmo, materialismo y demás regalías, contra los magistrados y potestades legitimas, V, Imprenta de Antonio Fernández, Madrid, 1775, pp. 292-293].

${ }^{11}$ MARTINEZ DIEZ, La tortura judicial, cit., pp. 292-293.

${ }^{12}$ Partida 7, 17, 6.

${ }^{13}$ Novísima Recopilación $12,28,8$ y 9.

${ }^{14}$ Partida 7, 28, 2 a 5.

${ }^{15}$ Ordenanzas Reales de Castilla 8, 9, 2.
} 
importancia concedida al arbitrio judicial, por otro, no constituían sino contraposiciones insalvables ${ }^{16}$.

Contra la tortura se había escrito bastante desde S. Agustín y Luis Vives ${ }^{17}$, pero es el P. Feijoo quien, por vez primera, utiliza argumentos de utilidad para poner en duda su eficacia, ya que -advierte- hay personas tan débiles que, al primer tormento, confiesan lo que se les pide aunque sea falso y otras tan pertinaces que siguen negando la verdad aunque se le apliquen los más duros tormentos ${ }^{18}$. Con razón y oportunidad observa D. Vicente de la Fuente que el mérito de Feijoo estriba en que publica su "Paradoja» sobre la tortura en 1734, anticipándose así en varios lustros a la polémica que entre los juristas españoles desencadenó la ya comentada «cuestión del tormento"19. Empero, el pensamiento del Padre Maestro dista mucho de ser paladinamente claro al respecto ${ }^{20} \mathrm{y}$, sobre todo, se muestra muy lejano del de su discípulo y amigo Fray Martín Sarmiento.

\footnotetext{
${ }^{16}$ TOMÁS Y VALIENTE, F., "La última etapa y ...”, cit., pp. 107.

${ }^{17}$ Vid., al respecto, ANTÓN ONECA, J., "El Derecho Penal de la Ilustración”, en Revista de Estudios Penitenciarios, 174 (1966), p. 599.

${ }^{18}$ Ya la décima de las Paradojas políticas y morales de Feijoo rezaba asi: La tortura es medio falible en la inquisición de los delitos y en ella, entre otras cosas, se señalaba: «Es innegable que el no confesar en el tormento, depende del valor para tolerarlo. Y pregunto, ¿el valor para tolerarlo depende de la inocencia del que está puesto en la tortura? Es claro que no, sino de la valentía del espíritu y robustez de ánimo que tiene. Luego la tortura no puede servir para averiguar la culpa o inocencia del que la está padeciendo» (...) "Parece, pues, que igualmente peligran en la tortura los inocentes que los culpables. ¡Terrible inconveniencia! Lo peor es que no es el peligro igual, sino de parte de los inocentes mayor. Diranme que ésta es una nueva paradoja, Confiésolo, pero si no me engaño, verdaderísima» (Cfr. Obras escogidas de Feijoo, en B.A.E. T. LVI, pp. 289 y ss).

19 MARTINEZ-RISCO, S., Las ideas jurídicas del Padre Feijoo, Orense, Instituto de Estudios Orensanos, 1973, p. 68. Para MARAVALL, J.A., constituye «uno de los timbres de gloria de Feijoo». (Cfr. Estudios de historia del pensamiento español. Siglo XVIII, Madrid, Ed. Cultura Hispánica, 1991, p. 201.

${ }^{20}$ En la Balanza de Astrea o recta administración de Justicia declara no horrorizarle que a los testigos falsos les corten en la India los pies y manos, y en Berna un magistrado les hiciera hervir en aceite (loc. cit. en GONZÁLEZ GUITIÁN, L., "Un predecesor de Beccaria”, en Estudios Penales y Criminológicos, I, Santiago de Compostela, 1988, p. 80 ss. Al respecto nos indica Concepción AMOR: "En una época en que el tormento como procedimiento judicial era cosa habitual corrientísima desde muchos siglos antes, era también bastante natural que no se sintiera con la intensidad que se siente hoy lo ofensivo y vejatorio que resulta a la dignidad humana. Por eso, Feijoo no tiene ni una sola palabra condenatoria del tormento en este sentido humano-social, sino que solamente lo encuentra absurdo porque resulta contraproducente para lograr el fin que persigue [Cfr. Ideas pedagógicas del Padre Feijoo (Madrid, C. S. I. C., 1950, p. 289]. Valentín SILVA MELERO, es todavía más crítico del pensamiento feijoniano sobre esta cuestión: "Sin embargo, el P. Feijoo, cuando trata de temas penales, ni se adelantó a la época, ni captó el ambiente que presagiaba tempestad y casi puede afirmarse que, en la ruta de la humanización penal, quedó rezagado en relación a más de uno de sus antecesores españoles e, incluso, de algún contemporáneo como el P. Sarmiento, su sombra, como dice el Dr. Marañón. Esto, naturalmente, no quiere decir que el P. Maestro no sintiera el problema penal ni menos que su espíritu iluminado por la caridad no vibrara ante el espectáculo de un sistema transido de crueldad. Sin embargo, ya habían surgido en España antes que Feijoo apareciera protestas contra el tormento y se había propuesto la humanización de las prisiones, tendencia nacida de la piedad cristiana, en el pensamiento de Cristóbal de Chaves, Bernardino de Sandoval y Cerdán de Tallada" [Cfr. "La faceta criminal en el pensamiento del P. Feijoo", en Anuario de Derecho Penal 9 (1956) p. 35]. Abunda en consideraciones parejas, Concepción Arenal cuando sostiene que Feijoo tenía hambre y sed de justicia pero que, en cambio, no tenía de la justicia en materia criminal una noción exacta, y que en esto, lejos de adelantarse a su época, le paga desdichado tributo, incorporándose a ella. Y agrega la señora ARENAL, "no por ignorancia del asunto, pues no era extraño al estudio penal, sino por sus exageradas ideas de la perversión de la naturaleza humana, y
} 
En efecto, la protesta de Sarmiento sobre la aplicación de la tortura judicial es mucho más airada y, podríamos decir, atrevida que las formuladas por su ilustre coetáneo. La tortura como medio de provocar la confesión era pieza esencial del proceso inquisitivo; por eso entendemos que todas las críticas que se hicieron de ella carecieron de coherencia y de fundamentación suficiente, ya que iban dirigidas únicamente contra ella y no contra el sistema procesal penal en su conjunto ${ }^{21}$. El acierto de Sarmiento consistió en plantear la crítica general de todo el sistema procesal inquisitivo y penal de su época. No presenta claro está, un tratado construido sistemáticamente; no obstante, en su pensamiento hay unos principios nucleares que conviene sintetizar: los modos de averiguar los hechos mediante tormento "son y serán siempre falsos, falaces y fallidos"22; deben rechazarse los juramentos como elemento probatorio ${ }^{23}$; en consecuencia, prefiere la prueba testifical ${ }^{24}$. Por la aplicación de la tortura peligran más los inocentes, a quienes sorprende su hábito de soportar el dolor, que los culpables, frecuentemente endurecidos por aquél; a mayor abundamiento, si se le aplica a un inocente, sus consecuencias pueden ser irreversibles e irreparables ${ }^{25}$. Como medio que se debe seguir para indagar la verdad de los hechos,

a pesar de ser compasivo y caritativo, como lo acredita su vida, se nos presenta duro cuando se trata de penar a la delincuencia" [Cfr. Juicio crítico sobre las obras de Feijoo, Madrid, Revista de España, 1877, p.38].

${ }^{21}$ Vid., en el mismo sentido TOMÁS Y VALIENTE, F., El Derecho Penal de la Monarquía Absoluta, $2^{\mathrm{a}}$ ed., Madrid, Tecnos, p. 173.

${ }^{22}$ SARMIENTO, F. M., Obra de Seiscientos Sesenta pliegos, Col. Dávila, fol. 270 r. A continuación, pormenoriza sobre las modalidades del tormento utilizadas en su época en estos términos: «El de Duelo y Desafío es notoriamente bárbaro sobre falaz, pues se confunde la mayor fuerza, y Destreza, con la verdad, y la Razón; y con razón está prohibido. Esto es entre Particulares, pero entre Príncipes independientes, es el más usado. Entre esos son Papeles mojados las Leyes; y como dixo vero; entre ellos sus Canones, son sus Cañones. Y si no median otros Reyes como Arbitros, que los Amisten gana el Pleyto el que tiene más fuerza; no el que tiene más Derecho» (fol. 270 v.). «Las Pruevas por agua o Hierro, además de ser falsas, como la del Duelo; y aver mil modos de tergiversarlos eran supersticiosas, y tentativas de la Omnipotencia divina, para que hiciese milagros» (fol. $271 \mathrm{r}$.).

${ }_{23}$ A propósito del juramento distingue entre medio de prueba y elemento de prueba; no tiene inconveniente en admitirlo como lo primero, pero se muestra reluctante a que actúe como pieza de convicción en la formación de la opinión del juzgador porque hay muchos "mentirosos" (fol. 271 r.).

${ }^{24}$ Ibid. Con todo, en fol. 267 v. Califica de poco fiable a la prueba testifical: "No hay cosa más fácil, que el hacer, una Información falsa, cuando el interesado es poderoso en riqueza, espada y en Vara alzada. Con tres o quatro quartillos de vino, o con algún tabaco está compuesto todo. Y lo peor es que, a veces, unos mismos testigos juran en dos informaciones encontradas. Así pide la Crítica que las deposiciones de Rústicos, en función de Sujetos Poderosos, se miren como sospechosos".

25 "El tormento es el medio más falaz, y dicen que el rey de Prusia le prohivió. Lo peor es que si después del tormento, se da por innocente, y este muere, o queda inútil para toda su vida; no he leído ley que castigue esa injusticia; y remedie esos daños» (folio 272 r.). Gaspar Melchor de JOVELLANOS, en su obra teatral El delincuente honrado, de 1773 -dedicada a poner de relieve lo injusto de la ley vigente entonces contra los duelistas, y en la que se crítica el arcaico modo de proceder de muchos magistrados-, se refiere incidentalmente a la tortura con estas palabras: "La tortura ¡Oh nombre odioso! ¡Nombre funesto! ¿Es imposible que en un siglo en que se respeta la humanidad y en que la filosofía derrama su luz por todas partes, se escuchen aún entre nosotros los gritos de la inocencia oprimida?" (Acto II, XIV, BAE 46, p. 29 b). No fue esta la única ocasión en que el ilustre asturiano se preocupó por el tema del tormento. Sabemos que, también durante su estancia en Sevilla - desde 1768 a 1778- como alcalde del crimen de su Audiencia redactó, al menos, tres informes de carácter procesal: un "Informe sobre el interrogatorio de los reos" y un tercer "Informe sobre la reforma de las cárceles". A los tres se refiere nuestro paisano Francisco SOMOZA DE MONSORIÚ, dándolos por perdidos [Cfr. Inventario de un jovellanista, Biblioteca Nacional, Madrid, 1901, p. 226-227). Es muy probable que tanto Sarmiento como Jovellanos conociesen la obra de Claude FERRIÉRE, Dictionaire de pratique, II, París, Veuve Brunet, 1740, en cuya página 612 se lee: "El tormento es un medio peligroso para llegar al conocimiento de la verdad; por eso los jueces no deben recurrir a el sin 
Sarmiento -que como el mismo se preocupa en señalar no habla como jurisperito ${ }^{26}$ rechaza la intimidación y postula por la prevención que se manifiesta en la represión de la avaricia y de la ociosidad ${ }^{27}$, todo ello merced a la aplicación de un aparato legislativo útil, claro, sencillo y preciso $^{28}$.

Con razón arguye Tomás y Valiente que en el fondo, entonces como ahora, se trata del mismo problema siempre: elegir entre un planteamiento ético, que valore la justicia y el respeto al hombre concreto por encima de todo, y otro planteamiento político lato sensu, que considere la eficacia como resultado óptimo deseable, al margen o en contra de consideraciones éticamente defendibles ${ }^{29}$. La tortura era y es eficaz en cuanto que con ella se logran a veces confesiones que sin su empleo no se pronunciarían. La tortura era y es injusta porque implica la fría y gratuita decisión de provocar sufrimientos a un ser humano; porque puede dar lugar a autoacusaciones o a delaciones falsas, $\mathrm{y}$, por tantas otras razones, éticamente incontroversibles. El sistema procesal-penal y el rey -legislador de entoncesoptaron por la violencia eficaz; hoy, otros que no siendo jueces, juristas ni legisladores realizan también lamentablemente la misma elección. Unos y otros anteponían y anteponen lo político, lo eficaz, a lo ético-jurídico.

Para Sarmiento, la realidad social que él presencia está llena de leyes injustas, sanguinarias y esotéricas. Su pretensión es abrir los ojos, sus conciudadanos ignorantes y combatir en pro de la necesaria reforma de aquéllas. El modo de combate por él elegido no es el estudio minucioso y técnico-jurídico de los delitos, sus formas y las penas contra cada uno de ellos; él se limita a mostrar los principios generales, las faltas más importantes y los errores más funestos del ordenamiento penal vigente.

El problema de la pena de muerte es el que dio lugar a más controversias y el que, sobre todo desde el Siglo de las Luces, dividió más las opiniones ${ }^{30}$. Seguramente ningún

reflexionar. Nada más equívoco. Hay culpables con la firmeza suficiente para ocultar un crimen verdadero..., otros, inocentes, a quienes la intensidad de los tormentos hace confesar crímenes de los que no son culpables".

${ }^{26}$ A la pregunta: “¿Qué medio se debe seguir para averiguar la verdad de un hecho”. Responde: “A mí no me toca el sellarle, ni soy de dictamen, que eso se encargue a juristas» (Ibid.).

27 "Dicese que los testamentos de Abogados, son una sentina de Pleytos. Los que han de entender en eso, deben atender a que la mejor medicina es la preservativa. Es imposible quitar los Delinquentes del Mundo aunque lluevan Leyes y Penas. La raiz de todos los Males y de los más de los Malos, es la Avaricia. Y la madre de todos los Vicios es la hociosidad. Como se espolee bien ésta, con Penas gravísimas, y se refrene aquélla con tasas prudenciales para todo está remediado mucho" (Ibid.).

28 "Los Castellanos Antiguos tenían pocas leyes; y todos eran interesados en que se observasen; y asi no tenían tanta infinidad de Hombres de Pluma, ni avía tantos Pleytos (Ibid). En línea con Montesquieu, Sarmiento define a la ley: "conforme Régla; norma justa equi, breve, concisa, clara, en idioma vulgar, útil, necesaria, que induzca y obligue inbonum, que retraiga del mal moral; constante, perpetua e inalterable" (fols. 225 r., 226 r.). También hace profesión de fe del pensamiento ciceroniano de que Simplicitas legum amica: Un letrado no tiene que servir para la inteligencia de la ley "pues si como es ley y justicia, que esa ley está en vulgar, clarísima, y que pueden entender todos, qualquiera la entenderá. Esto se palpa en los Bandos, cuyo contexto después de Pregonado, se fixa en las esquinas. Y sería necedad consultar abogados para entenderle. Y que son leyes, sino unos Bandos de larga duración" (folio. 266 v.).

29 TOMÁS Y VALIENTE, F., El Derecho Penal de la Monarquia Absoluta, cit., p. 175.

${ }^{30}$ CUELLO CALÓN, E., hace referencia a los tiempos pretéritos de la Ilustración en estos términos: «En los pasados siglos, los problemas de su legitimidad y conveniencia, objeto de viva controversia en la época 
medio penal ha sido más ardientemente combatido ni, por otra parte, defendido con la más firme convicción, ni más universalmente aplicado. Como ha señalado Rossi: "La historia nos enseña que el uso de la pena de muerte ha sido universal; se la encuentra establecida en todas las épocas y en todos los pueblos" 31 .

Las ideas abolicionistas no encontraron eco hasta el siglo XVIII. Se inicia en tonos moderados, no se pide su abolición total, sus aspiraciones son más limitadas; se pretende, tan sólo, restringir su campo de aplicación y la supresión de las espantosas torturas que comúnmente acompañaban a la muerte. Montesquieu, que pasa por ser uno de sus primeros precursores, consideraba lícita la última pena: "el hombre la merece, escribía, cuando ha violado la seguridad privando o intentando privar a otro de la vida, y es un remedio para la sociedad enferma" 32 . Tampoco Rousseau fue adversario de esta pena; inspirado en un sentido preventivista opinaba que la sociedad tiene el derecho de matar si no existe otro medio de impedir que se causen nuevas víctimas ${ }^{33}$. Uno de los espíritus señeros de la época, Goethe, no la impugnó ni en sus días de estudiante, ni después como hombre de estado; por el contrario, se manifestó en pro de su mantenimiento ${ }^{34}$. Lardizábal, sin duda el más conspicuo representante del iluminismo español en el ámbito jurídico-penal ${ }^{35}$, se mostró favorable a la punición capital ${ }^{36}$, dirigiendo incluso acerbas críticas a los abolicionistas $^{37}$. Incluso Beccaria, que pasa por ser uno de los iniciadores de la campaña

moderna, no inquietaban a los criminalistas, a los gobiernos ni a la opinión pública; nadie ponía en duda su utilidad ni justicia. En aquellos remotos días, sostener su posible abolición se hubiese recibido, al menos, como una extravagancia peligrosa» (Cfr. La moderna penología, Barcelona, Bosch, 1958, p. 113).

${ }^{31}$ ROSSI, P., Derecho Penal ${ }^{3}$, trad. esp., Madrid, Imprenta Repullés, 1839, p. 189.

${ }^{32} \mathrm{La}$ agresividad del individuo que se ha asociado a los otros es lo que explica la conveniencia de la pena, pero no la legitima. ¿Qué es lo que hace justo ese posible castigo que puede volverse contra cualquier miembro de la colectividad? Sencillamente que le ha estado protegiendo hasta el mismo instante en que se le ejecuta. Por si cupiese alguna duda, MONTESQUIEU lo ejemplifica en un caso bien extremo: "Lo que hace ilícita la muerte de un criminal es que la ley que lo castiga se ha hecho a favor suyo. Un asesino, por ejemplo, ha disfrutado de la ley que ahora le condena, pues le ha conservado la vida a cada instante, y por eso no puede reclamar contra ella" [Cfr. Del espiritu de las leyes, trad. esp. Ana Isabel Vega, Madrid, 1972, Dykinson, 2006, p. 53-54] . Sobre el tema, vid. GRAVEN, "Les conceptions pénales et l'actualité de Montesquieu”, en Rev. de Droit Pénal et de Criminologie (Bruselas, 1949), p. 161 y ss.

${ }^{33}$ ROUSSEAU, J. J., muestra una preocupación mucho menor en el momento de escribir sobre el castigo: la pena sirve para colocar a cada miembro de la colectividad en su parcela de libertades, evitando que se apropie de la de los otros: "Era preciso que los castigos se volviesen más severos a medida que las ocasiones de ofender se hacían más frecuentes y tocaba al terror a las venganzas ocupar el lugar del freno de las leyes" [Cfr. Del contrato social. Discursos, trad. esp., México, UNAM, 1962, p. 256-257].

${ }^{34}$ Goethe, en 1771, siendo estudiante en Estrasburgo, sostuvo su tesis doctoral: Poenae capitales non abrogandae. Vid., en este sentido, SCHMIDT, F., "Goethe und das Problem des Todesstrafe", en Schweizerische Zeitschriftf für Strafrecht (1948), p. 444 y ss.

${ }^{35}$ Así lo califica ANTÓN ONECA, "El Derecho Penal de la Ilustración y D. Manuel de Lardizábal” cit., pp. 607.

${ }^{36}$ Con todo, precisa algunas cautelas: "se debe usar de mucha circunspección y prudencia en imponer la pena capital, reservándola precisamente y con toda escrupulosidad para solos aquellos casos en que sea útil y absolutamente necesaria. La pena de muerte es como un remedio de la sociedad enferma, y hay casos en que es necesario cortar un miembro, para conservar el cuerpo» (Cfr. LARDIZÁBAL, M., Discurso sobre las penas contrahído á las leyes criminales de España para facilitar su reforma, Madrid, Imprenta Ibarra, $1782,11,4)$.

${ }^{37}$ Movidos acaso de esto -se refiere a los abusos cometidos en la aplicación de la pena de muertealgunos autores modernos, han dado en el extremo contrario, esforzándose a producir todas las razones que les ha sugerido su ingenio, para proscribir la pena capital como inútil y perniciosa, persuadiendo a los 
contemporánea contra la pena de muerte, admite dos motivos "que hacen necesaria la muerte de un ciudadano"38. El propio Feijoo, si bien no puede decirse que fuese su defensor a ultranza, propugnaba su mantenimiento. Veamos sobre este punto el pensamiento del sabio de Casdemiro:

"Dirásme acaso que esos daños no se remedian con que ese hombre muera, y así su muerte no hace más que añadir esta nueva tragedia a las otras. No se remedian esos daños; pero se precaven otros infinitos del mismo jaez. Los delitos perdonados son contagiosos; la impunidad de un delincuente inspira a otros osadía para serlo; y al contrario, su castigo, difundiendo una aprensión pavorosa en todos los mal intencionados, ataja mil infortunios. Ya que no puedes, pues, estorbar la desdicha de aquellos inocentes en quienes ya está hecho el daño, precave la de otros innumerables"39.

A la vista de lo expuesto, no podemos mostrarnos concordes con Martínez-Risco, cuando afirma que "los textos en que apoya -la pena de muerte- afloran serias dudas que pudieran interpretarse como vacilaciones o, al menos, debilidad en su actitud al respecto" 40 concluyendo que "los conceptos que emite al final de esa Paradoja Tercera dan paso a la creencia de que en el fondo de esa duda latía una idea abolicionista"41. Por contra, se muestra mucho más atinado en la captación del sentir feijoniano en punto a la pena capital, López Peláez, quien opina con su un tanto pretenciosa retórica decimonónica: "Con tener Feijoo ideas tan originales, tan independientes y tan atrevidas, y haber dirigido los formidables golpes de la demoledora piqueta de su crítica contra opiniones las más arraigadas y cimentadas más profundamente, se detuvo ante la pavorosa esfinge de la pena capital y quemó incienso en sus altares, en los cuales depositó el homenaje elocuente de su adhesión"42. Por nuestra parte, entendemos que el hecho de que Feijoo se encuadre en las filas de los apologistas de la pena capital y sea adversario del abolicionismo, ni le añade gloria, ni puede erigirse apriorísticamente en motivo de crítica per se, sobre todo teniendo

legisladores el total exterminio de ella en sus Códigos penales (...) Las razones en que se fundan los que quieren proscribir la pena de muerte, son ciertamente más ingeniosas que sólidas" (Cfr. Ibid., 1, 5).

38 "La muerte de un ciudadano sólo puede considerarse necesaria por dos motivos. El primero, cuando aún privado de libertad siga teniendo tales relaciones y tal poder que comprometa la seguridad de la nación, cuando su existencia pueda producir una peligrosa revolución en la forma de gobierno establecida. Asi pues, la muerte de un ciudadano se hace necesaria cuando la nación está en trance de recuperar o perder su libertad, o en tiempos de anarquía, cuando los mismos desórdenes sustituyen a las leyes" (Cfr. Cesare Bonesana, marqués de BECCARIA, De los delitos y de las penas, ed. Jordá, Barcelona, Bruguera, 1983, p. 104).

${ }^{39}$ FEIJOO, B. J., Teatro Crítico Universal, cit., T VI, "Paradojas políticas y morales, Paradoja tercera". Para Francisco PÉREZ FERRER, Feijoo es firme defensor de una utilitaria prevención general que ha de ser finalidad esencial de la pena. En otro lugar de su obra -añade- pone de manifiesto el sentido rigorista de su pensamiento: "El terror de las primeras ejecuciones reprime todos los genios aviesos y con cincuenta o cien ahorcados en el primer año de un reinado está hecho casi todo el gasto para mientras viva el príncipe". En vista de lo que antecede, nada tiene de extraño que el Padre Maestro se mostrase abierto defensor de la pena capital. Y ello por dos razones fundamentales: porque entonces, en su siglo, apenas si existía una voz abolicionista que se dejara oir y, porque vista la severidad de su concepción punitiva y la finalidad asignada al castigo, la pena de muerte reunía el máximo de aflicción que era preciso conseguir con ciertos delincuentes [Cfr. "Ideas penales y penitenciarias del P. Feijoo", en Revista de Estudios Penitenciarios 166 (1964) p. 44]

${ }^{40}$ MARTINEZ-RISCO, Las ideas jurídicas del Padre Feijoo, cit. p. 61.

${ }^{41}$ Ibid., p. 63.

${ }^{42}$ LÓPEZ PELÁEZ, A., Los escritos de Sarmiento y el siglo de Feijoo, La Coruña, Andrés Martínez, 1901, p. 157. 
en cuenta que, como hemos dicho, muchos de los espíritus señeros de la época se mostraban proclives a ello. Feijoo simplemente se limita a seguir la tesis de la prevención general defendida en aquellos tiempos por Montesquieu y Rousseau. Nadie mejor que Concepción Arenal para plasmar la esencia del sentir feijoniano: "La escuela a que pertenecía Feijoo no veía más que el derecho de la sociedad; el del reo desaparecía muchas veces en teoría y con mayor frecuencia aún en la práctica; el culpable era una criatura vil, infame, detestable, incorregible, objeto de desdén o de horror, y medio de escarmiento..." ${ }^{3}$.

En la gigantesca obra de Fray Martín Sarmiento se contienen páginas magistrales a favor de la tesis de que no existe teoría jurídica posible que justifique el mantenimiento de la pena capital. Por el gran interés que ofrecen, reproducimos algunas de sus opiniones sobre el particular, vertidas en su Obra de Seiscientos Sesenta pliegos, de manera concreta en el volumen $3^{\circ}$, folios 225 y 226 :

"Los Estados florecientes de la antigüedad tenían puesta pena de muerte a los ociosos; pues no ignoraban que la ociosidad era madre de todos los vicios; y entre ellos de los Vicios de pena capital... No tengo el jenio cruel. Sé que si los ociosos en España incurriesen en Pena de muerte se despoblaría toda ella.... Estoy en que por salvado que sea un Hombre, será más útil, vivo que muerto, a la Sociedad; si se le separa de ella en donde se le haga trabaxar. Es otro de que un castigo de muerte, sirve por escarmiento a otros; está bien pensado; pero no se corresponde en la práctica. Lo que logra, no es el escarmiento, pues cada día se multiplican las maldades de todo jénero. Lógrase sí, el quitar de enmedio estos y otros malvados. Quiténse enhorabuena estos malvados denmedio de la sociedad".

Dentro del iluminismo hispano, la originalidad de Sarmiento al pedir la supresión de la pena de muerte es palmaria. Para comprender la importancia que encierran las afirmaciones que siguen y la atención a que son acreedoras, basta fijarse en que chocaban con la opinión generalmente recibida y con la legislación de todos los países. Según sus propias palabras, la privación de la vida del reo es "bárbara, inútil y contraproducente". Aquí, una vez más, el pensamiento de Fray Martín se manifiesta mucho más radical que el de su amigo y maestro Feijoo ${ }^{44}$. Y es que, como ha señalado González López ${ }^{45}$, sus personalidades, a pesar de estar entrañablemente unidas por tres grandes afectos -la cultura, la Orden y, además, la tierra de su procedencia -eran muy distintas, como si su visión de la cultura en general estuviera separada por muchos años más en el tiempo y en el espacio. La explicación pudiera muy bien radicar en que Sarmiento no es hombre de su siglo y esa fue su desgracia, quedó muy adelantado para el siglo XVIII y muy retrasado para el nuestro ${ }^{46}$; de ahí que las consideraciones de su autoría en punto al tema que nos ocupa sólo puedan contemplarse desde esa perspectiva histórica.

\footnotetext{
${ }^{43}$ ARENAL, C., Juicio crítico de las obras de Feijoo, Madrid, Revista de España, 1987, p. 297.

${ }^{44}$ Acertadamente dice José Luis PENSADO: "Son tantas as diferencias que os separan, ou quezais mais, que as semellanzas que os unen. Si se examinase debidamente o pensamento de cada un deles ollaríamos que son enormemente diferentes, e o único que nos quedaría por vencellalos serían uns fortes nós de afeito e amistade" [Cfr. "Feijoo e Sarmiento. Duas vidas en pasado", en Grial 60 (1978) p. 129].

${ }^{45}$ GONZÁLEZ LÓPEZ, E., "Fray Martín Sarmiento e a conciencia da personalidade cultural de Galicia”, en Ibid. 43 (1974) p. 1.

${ }^{46}$ PENSADO, S.V. "Sarmiento, Fray Martín”, en Gran Enciclopedia Galega, Gijón 1973, ed. Silverio Cañada, p. 83.
} 
Hemos apuntado en páginas anteriores que Beccaria se pronunció contra la generalidad de los suplicios, pero admitía dos motivos "que hacen necesaria la muerte de un ciudadano" 47 . Sarmiento, por contra, solicita la abolición "en toda clase de delitos y crímenes". Su profesión de fe abolicionista obedece a que, para él (y esto lo sitúa a años luz de Feijoo y Beccaria) la aceptación del principio legal de la pena de muerte supone la aceptación de la filosofía de la violencia, en su aliento más profundo y más claro y la declaración de su necesidad. Si es lícito matar, todo es lícito.

La tesis del contrato social, sustentada por Beccaria, que se mostraba reluctante a la pena de muerte -salvo los casos excepcionales apuntados- basándose en que un hombre, por mucha autoridad que tenga, no puede dejarle a otro el arbitrio de dar muerte a un semejante $^{48}$, fue refutada ya en su tiempo porque lo mismo podría decirse de las demás penas ${ }^{49}$ y porque el freno más poderoso para cometer los delitos no es tanto el espectáculo momentáneo de la muerte del reo $^{50}$, como el ejemplo continuo de un hombre privado de libertad $^{51}$. En este sentido, Sarmiento incluso va mucho más allá de Bentham. Así, mientras el fundador del utilitarismo afirma que "los hombres, por lo general, miran la muerte como el mayor de todos los males y se someten a éstos para libertarse de aquélla" 52 . Sarmiento, por su parte, no cree únicamente en la intimidación: "lo que se da lugar no es el escarmiento, pues cada día se multiplican las maldades de todo género. Sólo es espantar moscas que cien veces espantadas, cien veces vuelven a ser moscas y a picar" 53 .

\section{BIBLIOGRAFÍA}

- AMOR, C., Ideas pedagógicas del Padre Feijoo, Madrid, C. S. I. C., 1950.

- ANTÓN ONECA, J., "El Derecho Penal de la Ilustración”, en Revista de Estudios Penitenciarios, 174 (1966).

- ARENAL, C., Juicio crítico sobre las obras de Feijoo, Madrid, Revista de España, 1877.

- BENTHAM, J., Rationale of Punishment, Londres, Bowring, 1830, I.

- BONESANA, C., marqués de BECCARIA, De los delitos y de las penas, ed. Jordá, Barcelona, Bruguera, 1983.

${ }^{47}$ Vid. la nt. 38.

${ }^{48}$ BECCARIA, formula la tesis en estos términos: “¿Quién es aquel que ha querido dejar a los otros hombres el arbitrio de dejarlo morir?" (Cfr. De los delitos y de las penas, cit., p. XXVIII).

${ }^{49}$ ANTÓN ONECA, "El Derecho Penal de la Ilustración", cit., p. 598.

${ }^{50}$ Durante largo tiempo se creyó que el espectáculo de las ejecuciones capitales, causaba sobre la muchedumbre que las presenciaba una saludable impresión de terror, que su siniestro recuerdo siempre perduraría en la memoria de los espectadores. Tal convicción explica la persistencia, hasta época muy próxima, de la pública ejecución de esta pena. Mas ya ha largo tiempo se reprocha a esta pena su falta de eficacia intimidatoria. El espectáculo de la ejecución pública de la pena de muerte ante enorme muchedumbre que acudía a contemplarla se ha alegado que lejos de producir, como antes se creía, una indeleble impresión de terror, constituía una fiesta repugnante y desmoralizadora, acerca de cuyo influjo corruptor sobre las masas están de acuerdo adversarios y defensores de la pena capital (Literatura al respecto en CUELLO CALÓN, E., La moderna penología, cit., p. $140 \mathrm{ss}$ ).

${ }^{51}$ Más que la muerte sería elocuente "el ejemplo de un hombre a quien se tiene siempre ante los ojos, a quien se ha privado de la libertad y que está obligado a emplear el resto de su vida en reparar la pérdida que ha causado a la sociedad" (Cfr. BOUCHER D'ARGIS, A., Observations sur les lois criminelles, París, Leboucher, 1781, p. 139).

${ }^{52}$ BENTHAM, J., Rationale of Punishment, Londres, Bowring, 1830, I, p. 441-450.

${ }^{53}$ SARMIENTO, F. M., Obra de Seiscientos, cit., vol. 3, fol. 225. 
- BOUCHER D’ARGIS, A., Observations sur les lois criminelles, París, Leboucher, 1781.

- CERDÁN DE TALLADA, T., Verdadero Gobierno de esta Monarquía tomando por su propio sujeto la conservación de la paz, Valencia, Imprenta Viuda de Pedro de Huete, 1581.

- CUELLO CALON, E., La moderna penología, Barcelona, Bosch, 1958.

- Diccionario histórico de la Ilustración, Madrid, Alianza Editorial, 1998, eds. Ferrere y Roche.

- DORADO MONTERO, P., El derecho protector de los criminales, Madrid, Librería General de Victoriano Suárez, 1915.

- EYMERICH, N., Directorium inquisitorium cum commentariis Francisci Pegnae, apud Marcum Antonium Zalterium, 1587.

- FERNÁNDEZ RODRÍGUEZ, M. ${ }^{a}$ D., El pensamiento penitenciario y criminológico de Rafael Salillas, Santiago de Compostela, Servicio de Publicaciones de la Universidad, 1976.

- FERRIÉRE, C., Dictionaire de pratique, II, París, Veuve Brunet, 1740.

- FOUCAULT, M., Vigilar y castigar, Madrid, Editorial Siglo XXI, 1998.

— GARÇON, E., Droit Penal, París, Ed. Payot, 1922.

- GONZÁleZ GUITIÁN, L., Estudios Penales y Criminológicos, I, Santiago de Compostela, 1988.

- GONZÁLEZ LÓPEZ, E., "Fray Martín Sarmiento e a conciencia da personalidade cultural de Galicia", en Grial 43 (1974).

- GRAVEN, J., "Les conceptions pénales et l'actualité de Montesquieu”, en Rev. de Droit Pénal et de Criminologie (Bruselas, 1949).

— JIMÉNEZ DE ASÚA, L., Tratado de Derecho Penal, Buenos Aires, Editorial Losada, 1964, I.

— JOBÍM, L., "La inquisición portuguesa y la Ilustración: I Proyecto de reforma de Melo Freire", en Perfiles jurídicos de la Inquisición Española ed. J.A. Escudero, Madrid, Universidad Complutense, 1989.

- LARDIZÁBAL, M., Discurso sobre las penas contrahído á las leyes criminales de España para facilitar su reforma, Madrid, Imprenta Ibarra, 1782.

- LÓPEZ PELÁEZ, A., Los escritos de Sarmiento y el siglo de Feijoo, La Coruña, Andrés Martínez, 1901.

- MARAVALL, J.A., Estudios de historia del pensamiento español. Siglo XVIII, Madrid, Ed. Cultura Hispánica, 1991.

- MARTÍNEZ DÍEZ, G., "La tortura judicial en la legislación histórica española”, en Anuario de Historia de Derecho Español 32 (1962).

- MARTINEZ-RISCO, S., Las ideas jurídicas del Padre Feijoo, Orense, Instituto de Estudios Orensanos, 1973.

- MONTESQUIEU, C.L., Del espiritu de las leyes, trad. esp. Ana Isabel Vega, Madrid, 1972, Dykinson, 2006.

— PENSADO, J.L., "Feijoo e Sarmiento. Duas vidas en pasado", en Grial 60 (1978).

- PENSADO, S.V. "Sarmiento, Fray Martín", en Gran Enciclopedia Galega, Gijón 1973, ed. Silverio Cañada.

- PÉREZ FERRER, F., "Ideas penales y penitenciarias del P. Feijoo", en Revista de Estudios Penitenciarios 166 (1964).

- ROSSI, P., Derecho Penal ${ }^{3}$, trad. esp., Madrid, Imprenta Repullés, 1839.

— ROUSSEAU, J. J., Del contrato social. Discursos, trad. esp., México, UNAM, 1962.

- SALILLAS, R., Evolución penitenciaria de España, Madrid, Imprenta Clásica de España, 1916.

- SARMIENTO, F. M., Obra de Seiscientos Sesenta pliegos, Col. Dávila.

- SCHMIDT, F., "Goethe und das Problem des Todesstrafe", en Schweizerische Zeitschriftf für Strafrecht (1948).

— SILVA MELERO, V., "La faceta criminal en el pensamiento del P. Feijoo", en Anuario de Derecho Penal 9 (1956).

- SOMOZA DE MONSORIÚ, F., Inventario de un jovellanista, Biblioteca Nacional, Madrid, 1901.

- TOMÁS Y VALIENTE, F., El Derecho Penal de la Monarquía Absoluta, $2^{\mathrm{a}}$ ed., Madrid, Tecnos.

- TOMÁS Y VALIENTE, F., "La última etapa y la abolición de la tortura judicial en España", en Anales de la Universidad de La Laguna. Facultad de Derecho, 1963-1964= La tortura en España ${ }^{2}$ ed. Ariel, Madrid, 1994.

- TRINIDAD FERNÁNDEZ, P., La reforma de la sociedad. Cárcel y delincuencia en España (siglos XVIIIXIX), Madrid, Alianza Editorial, 1991.

— VILAR, P., Economía, Derecho, Historia, Barcelona, Ariel, 1983. 